\title{
Hubungan Praktek Manajemen dengan Ketidakhadiran Petugas Puskesmas di Kabupaten Wakatobi Tahun 2018
}

\author{
Candra Candra ${ }^{1}$, Nurul Inaini Febriarini ${ }^{2}$, Husnul Khatimah ${ }^{3}$ \\ 1,2,3 Program Studi D3 Keperawatan, Stikes Al Islam Yogyakarta, Daerah Istimewa Yogyakarta \\ email: chandra_laskar@yahoo.com ${ }^{1}$, nurulif@gmail.com ${ }^{2}$,ima.chan29@gmail.com ${ }^{3}$
}

\begin{abstract}
As the most important point of contact for health services, the presence of health workers at the Puskesmas must be a serious concern. If it is not managed and controlled, absenteeism can spread like a pandemic and will create various disciplinary problems for the organization. This study aims to measure the relationship between the management practices of the Puskesmas and abseteeism of Puskesmas officers in Wakatobi Regency.This study use quantitative methods with cross-sectional survey method. Samples were health worker in the Puskesmas 141 people. Data analysis using Stata 12 software. This study shows that Puskesmas management practices seen from work attitudes influence the absence of Puskesmas officers where Puskesmas officers who have poor work attitudes are more often absent, job satisfaction affects the absence of Puskesmas officers where dissatisfied Puskesmas officers have more absenteeism high. Supervision has an effect on the absence of Puskesmas officers where Puskesmas officers who get poor supervision have a higher absence rateThe absence of Puskesmas officers in the Wakatobi Regency area is still very high. The high absenteeism of this relates to poor health center management practices.
\end{abstract}

Keywords: Practices Management, Health Worker, Absenteeism, Human Resources for Health

\begin{abstract}
ABSTRAK
Sebagai titik kontak layanan kesehatan yang paling utama, kehadiran tenaga kesehatan di Puskesmas harus menjadi perhatian serius. Jika tidak dikelola dan dikendalikan, ketidakhadiran bisa menyebar seperti pandemi dan akan menciptakan berbagai masalah disiplin bagi organisasi. Untuk itu, penelitian ini bertujuan mengukur hubungan praktik manajemen Puskesmas dengan ketidakhadiran petugas Puskesmas di Kabupaten Wakatobi. Penelitian ini menggunakan metode kuantitatif dengan metode cross sectional survey.Sampel penelitian ini tenaga medis (dokter dan dokter gigi), perawat dan bidan yang bekerja di Puskesmas berjumlah 141 orang. Analisis data menggunakan software Stata 12.

Penelitian ini menunjukkan bahwa praktik manajemen Puskesmas dilihat dari sikap kerja berpengaruh terhadap ketidakhadiran petugas Puskesmas dimana petugas Puskesmas yang memiliki sikap kerja kurang baik lebih sering tidak hadir, kepuasan kerja berpengaruh terhadap ketidakhadiran petugas Puskesmas dimana petugas Puskesmas yang tidak puas memiliki tingkat ketidakhadiran yang lebih tinggi. Supervisi berpengaruh terhadap ketidakhadiran petugas Puskesmas dimana petugas Puskesmas yang mendapatkan supervisi yang kurang baik memiliki tingkat ketidakhadiran yang lebih tinggi.

Kata kunci: Praktik Manajemen, Petugas Puskesmas, Ketidakhadiran, Sumber Daya Manusia Kesehatan.

\section{PENDAHULUAN}

Tenaga kesehatan merupakan tulang punggung terlaksananya kegiatan Puskesmas dan berperan penting dalam pencapaian tujuan Puskesmas. Sebagai titik kontak layanan kesehatan yang paling utama, kehadiran tenaga kesehatan di Puskesmas harus menjadi perhatian serius. Jika tidak dikelola dan dikendalikan, ketidakhadiran bisa menyebar seperti pandemi dan akan menciptakan berbagai

masalah disiplin bagi organisasi (Hoque \& Islam 2003). Tanpa adanya tenaga kesehatan di Puskesmas proses layanan kesehatan tidak akan berjalan (Wananda et al., 2015).

Dari perspektif sistem kesehatan, ketidakhadiran merupakan keadaan kronis, meninggalkan pekerjaan saat jam kerja resmi yang mempengaruhi produktifitas tenaga kesehatan dan merusak kualitas layanan kesehantan (WHO, 2006; Deussom et al, 2012).
\end{abstract}


Roggers et al, menyatakan bahwa perilaku kehadiran karyawan merupakan fungsi dari dua variabel: 1) kemampuan untuk hadir, dan 2) motivasi untuk hadir. Karyawan yang bersedia hadir dapat terpengaruh oleh tekanan negatif termasuk respons afektif terhadap situasi pekerjaan (motivasi internal) dan berbagai tingkat tekanan eksternal dari yang tidak dapat dihindari (misalnya, penyakit, kecelakaan, tanggung jawab keluarga) atau tekanan yang dapat dihindari (misalnya, stres karena beban pekerjaan, lingkungan kerja, gaya kepemimpinan dan masalah administratif lainnya) (Kisakye et al., 2016)

Secara global, sekitar 7\% dari petugas kesehatan dilaporkan setidaknya satu kali tidak hadir dalam satu minggu. Ketidakhadiran tenaga kesehatan merupakan fenomena yang sering terjadi di fasilitas kesehatan dibanyak negara berkembang di Asia dan Afrika, terutama di daerah miskin sumber daya beberapa diantaranya India (Banerjee dan Duflo 2006 ), Kenya (Goldstein et al, 2010), Bangladesh (Chaudhury and Hammer, 2003), Kosta Rika (García-Prado and Chawla, 2006) dan Indonesia (Pratikno Ramadhan, 2013). Bank dunia (2003) menemukan ketidakhadiran tenaga kesehatan diberbagai negara berkembang melalui kunjungan tidak terjadwal ke fasilitas pelayanan kesehatan masyarakat dengan rata-rata tingkat ketidakhadiran tenaga kesehatan sebanyak 35\% (Chaudhury et al, 2006b). Penelitian yang dilakukan Di Tella dan Savedoff (2001) menunjukkan spesialis dan dokter senior di Venezuela kehilangan sekitar sepertiga dari jam layanan kontrak mereka, sementara bidan dan perawat dengan tingkat ketidakhadiran sekitar $13 \%$ dan $7 \%$.

Indonesia menduduki peringkat pertama dalam tingkat ketidakhadiran tenaga kesehatan di antara negara-negara lainnya dengan persentase $40 \%$ lebih parah dari Peru sebanyak 25\% ,Bangladesh 35\% dan Uganda sebanyak $37 \%$. Sebuah survey nasional pada tahun 2002/2003 yang dilakukan oleh lembaga SMERU menunjukkan tingkat ketidakhadiran petugas kesehatan di Puskesmas yaitu 27,9\% (The SMERU Research Institute, 2004). Penelitian yang sama juga dilakukan oleh Ramadhan di kota Bengkulu dengan temuan tingkat ketidakhadiran yang tidak jauh berbeda yaitu 23,4\% (Ramadhan and Santoso, 2015).

Keberhasilan upaya pemberian layanan kesehatan yang efektif, efisien dan responsif terhadap kebutuhan masyarakat tergantung pada kapasitas dan kemauan petugas kesehatan untuk memberikan layananan yang berkualitas dan relevan (WHO). Perilaku petugas Puskesmas dipengaruhi oleh kondisi kerja dan insentif dan lingkungan tempat kerja, akibatnya tujuan petugas kesehatan terkadang menyimpang dari kebijakan di tempat kerja. Dengan tidak adanya instentif yang tepat, sistem monitoring yang buruk dan sanksi yang tidak kredibel maka akan menimbulkan ketidakpuasan dan tujuan organisasi tidak akan tercapai (Lewis, 2009). Misalnya, beberapa dokter mungkin sebagian atau sama sekali tidak hadir, kurang tekun bekerja, atau dengan mudah dan sering terlibat dalam praktik ganda meskipun ada batasan hukum.(García-Prado and González, 2011).

Ketidakhadiran sejumlah staf akhirnya berpengaruh terhadap kinerja Puskesmas dalam memberikan pelayanan kesehatan kepada masyarakat. Demikian pula secara internal, perilaku tidak patuh dan semaunya sendiri mempengaruhi kinerja staf Puskesmas lain karena tidak ada sanksi tegas kepada para staf kecuali surat peringatan. Akhirnya ketidakhadiran menyebabkan kekompakan tim Puskesmas terganggu. Pelayanan kesehatan semakin lama semakin terganggu misalnya Puskesmas tidak buka setiap hari. Layanan yang seharusnya ada di Puskesmas tetapi tidak bisa diberikan karena tidak ada petugas, jam kerja semakin pendek. Berangsur-angsur Puskesmas semakin sepi. Masyarakat terpaksa harus ke Puskesmas lain atau ke dokter praktek untuk mendapatkan layanan kesehatan.

Wakatobi merupakan salah satu kabupaten di Sulawesi Tenggara yang terdiri dari gugusan pulau-pulau dan termasuk salah satu kabupaten dalam kriteria Daerah Terpencil, Perbatasan dan Kepulauan (DTPK). Fasilitas kesehatan dasar yang beroperasi di wilayah Kabupaten Wakatobi sekitar 20 Puskesmas dengan sebaran 6 Puskesmas di pulau Tomia, 4 Puskesmas di pulau Binongko, 5 Puskesmas di pulau Kaledupa, dan 5 Puskesmas di pulau Wanci, dengan tenaga kesehatan sebanyak 12 Dokter, 3 Dokter Gigi, 156 Tenaga Keperawatan, dan 83 Bidan (BPS Kabupaten Wakatobi, 2016). Jumlah tenaga kesehatan yang sesuai, distribusi tenaga yang proporsioanal, dan kemampuan sesuai sangat membantu sistem pelayanan kesehatan utama berfungsi dengan baik. Tenaga kesehatan juga seharusnya selalu hadir di unit dimana mereka ditugaskan, agar sistem ini dapat berfungsi dengan baik dalam memberikan pelayanan kesehatan. Kebiasaan sebagian 
tenaga kesehatan yang tidak hadir menyebabkan kesenjangan akses masyarakat terhadap pelayanan kesehatan. (USAID Kinerja, 2017)

Berdasarkan uraian di atas maka peneliti tertarik meneliti tentang hubungan praktik manajemen dengan ketidakhadiran petugas Puskesmas di Kabupaten Wakatobi untuk melihat seberapa efektif penerapan manajemen Puskesmas.

\section{METODE PENELITIAN}

Penelitian ini merupakan penelitian kuantitatif dengan pendekatan cross sectional yaitu suatu pendekatan yang mempelajari dinamika korelasi antara faktor-faktor dan efek, observasi atau pengumpulan data sekaligus (point time approch). Populasi dalam penelitian ini seluruh petugas Puskesmas di Kabupaten Wakatobi sebanyak 254 orang. Penelitian ini dilakukan di Kabupaten Wakatobi dengan besaran sampel 141 petugas Puskesmas. Hari kerja ASN di Kabupaten Wakatobi berlaku 5 hari kerja dengan jam kerja mulai jam 07.0016.00 WITA. Sehingga peneliti melakukan pengambilan data dengan 2 kali kunjungan yaitu pada jam 09.00-11.00 pagi dan jam 14.30-15.45 Sore. Hal ini dilakukan untuk memastikan ketidakhadiran petugas Puskesmas di Kabupaten Wakatobi. Setelah data dikumpukan kemudian diolah dan disajikan dalam bentuk tabulasi distribusi frekuensi, dan dipresentasikan. Pengolahan dan analisis data dengan menggunakan STATA versi 12

\section{HASIL}

1. Alasan Ketidakhadiran Petugas
Puskesmas
Tabel 1 menunjukkan alasan
ketidakhadiran petugas Puskesmas di
Kabupaten Wakatobi. Ketidakhadiran petugas
Puskesmas lebih banyak terjadi karena petugas
belum datang dan paling sedikit terjadi karena
sakit/ijin. Hal ini membuktikan bahwa tingginya
budaya permisif Puskesmas pada petugas
Puskesmas.

\begin{tabular}{lcc}
\hline \multicolumn{1}{r}{ Alasan } & $\mathrm{n}$ & $\%$ \\
\hline Sedang Tidak & 5 & 14,29 \\
Bertugas & 3 & 8,57 \\
Libur & 8 & 22,86 \\
Dinas Keluar & 2 & 5,71 \\
Sakit/Ijin & 11 & 31,43 \\
Belum Datang & 6 & 17,14 \\
Mangkir/Bolos &
\end{tabular}

Sumber: Data Primer 2018

2. Karakteristik Petugas Puskesmas di Kabupeten Wakatobi

Analisis univariat mendeskripsikan distribusi frekuensi untuk semua variabel penelitian yang terdiri dari ketidakhadiran petugas Puskesmas, jenis kelamin, jenis tenaga, masa kerja, status parenthood, jarak, praktik ganda dan sikap kerja, kepuasan kerja, komitmen, dan supervisi.

Tabel 2 menunjukkan bahwa ketidakhadiran petugas Puskesmas di Kabupaten Wakatobi mencapai angka 24,82\%. Hal ini menunjukkan bahwa Puskesmas dalam kondisi "tidak sehat". Tingginya tingkat ketidakhadiran membuktikan bahwa buruknya praktik manajemen di Puskesmas wilayah Kabupaten Wakatobi.

Data menunjukkan petugas Puskesmas di wilayah Kabupaten Wakatobi sangat didominasi oleh perempuan $(66,67 \%)$ dibanding laki-laki $(33,33 \%)$. 
Tabel 2. Distribusi Frekuensi Variabel Penelitian Ketidakhadiran Petugas Puskesmas di Kabupeten Wakatobi tahun 2018

\begin{tabular}{|c|c|c|}
\hline Variabel & $\mathrm{n}$ & $\%$ \\
\hline \multicolumn{3}{|l|}{ Ketidakhadiran } \\
\hline hadir & 106 & 75,18 \\
\hline tidak hadir & 35 & 24,82 \\
\hline \multicolumn{3}{|l|}{ Jenis kelamin } \\
\hline laki-laki & 47 & 33,33 \\
\hline perempuan & 94 & 66,67 \\
\hline \multicolumn{3}{|l|}{ Jenis Tenaga } \\
\hline Dokter & 9 & 6,38 \\
\hline Perawat & 73 & 51,78 \\
\hline Bidan & 25 & 17,73 \\
\hline Bidan desa & 10 & 7,09 \\
\hline Paramedis & 24 & 17,02 \\
\hline \multicolumn{3}{|l|}{ Lama kerja } \\
\hline$\leq 4$ tahun & 93 & 65,96 \\
\hline$>4$ tahun & 48 & 34,04 \\
\hline \multicolumn{3}{|l|}{ Status parenthood } \\
\hline tidak memiliki anak & 100 & 70,92 \\
\hline memiliki anak & 41 & 29,08 \\
\hline \multicolumn{3}{|l|}{ Jarak tempat tinggal } \\
\hline$\leq 3 \mathrm{~km}$ & 87 & 61,7 \\
\hline$>3 \mathrm{~km}$ & 54 & 38,3 \\
\hline \multicolumn{3}{|l|}{ Praktik ganda } \\
\hline solo praktik & 129 & 91,49 \\
\hline dual praktik & 12 & 8,51 \\
\hline \multicolumn{3}{|l|}{ Sikap Kerja } \\
\hline baik & 104 & 73,76 \\
\hline kurang baik & 37 & 26,24 \\
\hline \multicolumn{3}{|l|}{ Kepuasan kerja } \\
\hline puas & 95 & 67,38 \\
\hline tidak puas & 46 & 32,62 \\
\hline \multicolumn{3}{|l|}{ Komitmen Organisasi } \\
\hline baik & 99 & 70,21 \\
\hline kurang Baik & 42 & 29,79 \\
\hline \multicolumn{3}{|l|}{ Supervisi } \\
\hline Baik & 104 & 73,76 \\
\hline kurang Baik & 37 & 26,24 \\
\hline
\end{tabular}

Sumber: Data Primer, 2018

Jenis tenaga yang paling banyak terdistribusi di Puskesmas yaitu tenaga perawat $(51,78 \%)$ dan terendah tenaga dokter (6,38\%). Puskesmas di wilayah Kabupaten Wakatobi didominasi petugas dengan masa kerja di bawah atau sama dengan empat tahun $(65,96 \%)$ dibanding petugas Puskesmas dengan masa kerja diatas empat tahun (34,04\%). Selain itu, Puskesmas di wilayah Kabupaten Wakatobi didominasi petugas dengan jarak tempat tinggal petugas Puskesmas dibawah atau sama dengan 3 kilometer $(61,7 \%)$ dibanding diatas tiga kilometer $(38,3 \%)$ dari Puskesmas.

Data juga menunjukkan Puskesmas di Wilayah Kabupaten Wakatobi didominasi oleh petugas Puskesmas yang tidak memiliki anak $(70,92 \%)$ dibanding petugas yang memiliki anak $(29,08 \%)$. Selain itu, data juga menunjukkan bahwa Puskesmas didominasi oleh petugas yang praktik solo $(91,49 \%)$ dibanding petugas yang memiliki praktik ganda (8,51\%). Sikap kerja menunjukkan 73,76\% petugas Puskesmas memiliki sikap kerja yang baik dan 26,24\% petugas Puskesmas memiliki sikap kerja yang kurang baik. Data kepuasan kerja menunjukkan bahwa terdapat 67,38\% petugas Puskesmas menyatakan puas dan $32,62 \%$ petugas Puskesmas tidak puas. Data komitmen organisasi petugas puskesmas menunjukkan terdapat $70,21 \%$ petugas kesehatan memiliki komitmen organisasi yang baik dan 29,79\% memiliki komitmen organsasi yang kurang baik. Serta, supervisi petugas Puskesmas menunjukkan terdapat $73,78 \%$ menyatakan supervisi baik dan 26,24 supervisi kurang baik.

\section{Ketidakhadiran Petugas Puskesmas}

Dalam analisis tabulasi silang dilakukan uji chi-square $\left(\mathrm{X}^{2}\right)$ dengan menyesuaikan data yang ada yaitu data kategorik. Hubungan antara variabel dependen dan variabel independen dianggap bermakna jika nilai $\mathrm{p}<0,05$ dengan confident interval $95 \%$

Tabel 3 menunjukkan analisis bivariat antara variabel jenis tenaga dengan ketidakhadiran petugas Puskesmas tidak terdapat hubungan yang bermakna secara statistik antara jenis tenaga dengan ketidakhadiran petugas Puskesmas. Namun secara statistisk menunjukkan bidan lebih sering tidak hadir dibanding dengan dokter dan petugas Puskesmas lainnya

Analisis bivariat antara praktik ganda dengan ketidakhadiran petugas Puskesmas menunjukkan $p$ value $=0,1564$ dengan $\mathrm{OR}=$ 2,36 yang berarti bahwa tidak terdapat hubungan yang bermakna secara statistik antara praktik ganda dengan ketidakhadiran petugas Puskesmas dimana petugas Puskesmas yang dual praktik lebih sering tidak hadir dibanding petugas Puskesmas yang solo praktik. 
Tabel 3. Analisis Bivariat Ketidakhadiran Petugas Puskesmas dengan Variabel Penelitian di Puskesmas Kabupaten Wakatobi tahun 2018

\begin{tabular}{|c|c|c|c|c|c|c|c|c|}
\hline \multirow{3}{*}{ Variabel } & \multirow{3}{*}{$\mathrm{N}$} & \multicolumn{4}{|c|}{$\begin{array}{c}\text { Ketidakhadiran Petugas } \\
\text { Kesehatan } \\
\end{array}$} & \multirow{3}{*}{ OR } & \multirow{3}{*}{$p$ value } & \multirow{3}{*}{ CI $95 \%$} \\
\hline & & \multicolumn{2}{|c|}{ Hadir } & \multicolumn{2}{|c|}{ Tidak Hadir } & & & \\
\hline & & $\mathrm{n}$ & $\%$ & $\mathrm{~N}$ & $\%$ & & & \\
\hline \multicolumn{9}{|l|}{ Jenis Tenaga } \\
\hline Dokter & 9 & 6 & 66,7 & 3 & 33,3 & 1 & & \\
\hline Perawat & 73 & 58 & 79,45 & 15 & 20,55 & 1,93 & 0,3849 & $0.43-8.79$ \\
\hline Bidan & 25 & 21 & 84 & 4 & 16 & 2,63 & 0,2773 & $0,43-16,03$ \\
\hline Bidan desa & 10 & 6 & 60 & 4 & 40 & 0,75 & 0,7697 & $0,11-5,18$ \\
\hline Paramedis & 24 & 15 & 62,5 & 9 & 37,5 & 0,83 & 0,8273 & $0,16-4,29$ \\
\hline \multicolumn{9}{|l|}{ Praktik ganda } \\
\hline Solo praktik & 129 & 99 & 76,74 & 30 & 23,26 & 1 & & \\
\hline Dual praktik & 12 & 7 & 58,33 & 5 & 41,67 & 2,36 & 0,1564 & $0,69-8,07$ \\
\hline \multicolumn{9}{|l|}{ Sikap Kerja } \\
\hline Baik & 104 & 84 & 80,77 & 20 & 19,23 & 1 & & \\
\hline Kurang Baik & 37 & 22 & 59,46 & 15 & 40,54 & 2,86 & 0,0102 & $1,24-6,64$ \\
\hline \multicolumn{9}{|l|}{ Kepuasan kerja } \\
\hline Puas & 95 & 77 & 81,05 & 18 & 18,95 & 1 & & \\
\hline Tidak puas & 46 & 29 & 63,04 & 17 & 36,96 & 2,51 & 0,0207 & $1,12-5,62$ \\
\hline \multicolumn{9}{|c|}{ Komitmen Organisasi } \\
\hline Baik & 99 & 77 & 77,78 & 22 & 22,22 & 1 & & \\
\hline Kurang Baik & 42 & 29 & 69,05 & 13 & 30,95 & 1,56 & 0,2741 & $0,69-3,54$ \\
\hline \multicolumn{9}{|l|}{ Supervisi } \\
\hline Baik & 104 & 83 & 79,81 & 21 & 20,19 & 1 & & \\
\hline Kurang Baik & 37 & 23 & 62,16 & 14 & 37,84 & 2,41 & 0,0335 & $1,04-5,54$ \\
\hline
\end{tabular}

\section{Sumber: Data Primer, 2018}

Analisis bivariat antara variable sikap kerja dengan ketidakhadiran petugas Puskesmas menunjukkan $p$ value $=0,0102$ dengan $\mathrm{OR}=$ 2,86 yang berarti bahwa terdapat hubungan yang bermakna secara statistik antara sikap kerja dengan ketidakhadiran petugas Puskesmas dimana sikap kerja petugas Puskesmas yang kurang baik lebih sering tidak hadir dibanding sikap kerja petugas Puskesmas yang baik.

Analisis bivariat antara variable kepuasan kerja dengan ketidakhadiran petugas Puskesmas menunjukkan $p$ value $=0,0207$ dengan $\mathrm{OR}=$ 2,51 yang berarti bahwa terdapat hubungan yang bermakna secara statistik antara kepuasan kerja dengan ketidakhadiran petugas Puskesmas dimana petugas Puskesmas yang tidak puas lebih sering tidak hadir dibanding petugas Puskesmas yang puas.

Analisis bivariat antara komitmen organisasi dengan ketidakhadiran petugas Puskesmas menunjukkan $p$ value $=0,2741$ dengan $\mathrm{OR}=$ 1,56 yang berarti bahwa tidak terdapat hubungan yang bermakna secara statistik antara komitmen organisasi dengan ketidakhadiran petugas Puskesmas dimana petugas Puskesmas yang memiliki komitmen kurang baik lebih sering tidak hadir dibanding petugas Puskesmas yang memiliki komitmen organisasi baik.

Sedangkan, analisis bivariat antara variable supervisi dengan ketidakhadiran petugas Puskesmas menunjukkan $p$ value $=0,0335$ dengan $\mathrm{OR}=2,41$ yang berarti bahwa terdapat hubungan yang bermakna secara statistik antara supervisi dengan ketidakhadiran petugas Puskesmas dimana petugas Puskesmas yang mendapatkan supervisi yang kurang baik lebih sering tidak hadir dibanding petugas Puskesmas yang mendapatkan supervisi yang baik.

\section{PEMBAHASAN}

Hasil penelitian ini menunjukkan bahwa petugas Puskesmas berjenis kelamin perempuan lebih sering tidak hadir dibandingkan Laki-Laki. Penelitian ini selaras dengan penelitian Wananda, et al (2015) menyatakan petugas kesehatan berjenis kelamin laki-laki memiliki tingkat kehadiran yang lebih tinggi. Namun hasil penelitian ini bertentangan dengan studi yang di lakukan Ritchie, et al (1999) yang menunjukkan bahwa perempuan lebih mungkin 
tidak hadir dibandingkan laki-laki. Robbins (2003) mengemukakan bahwa wanita lebih absen dibanding laki-laki karena wanita yang bekerja memiliki peran ganda sebagai ibu, mengurus rumah dan sebagainya. Hal yang berbeda di kemukakan Chaudhury, et al (2006), bahwa tidak ada perbedaan yang signifikan dalam tingkat ketidakhadiran antara laki-laki dan perempuan tetapi secara praktis wanita lebih sering tidak hadir dibanding laki-laki.

Otonomi dalam pekerjaan membuat individu lebih leluasa dalam menjadwalkan pekerjaan dan menentukan prosedur yang harus di gunakan dalam melaksanakan pekerjaanya untuk melihat signifikansi kontribusi mereka (Hackman and Oldham, 1976). Ketika kontribusi individu dalam pekerjaanya bermakna, maka karyawan lebih cenderung terlibat dalam pekerjaan tersebut. Kewenangan untuk membuat keputusan independen hasil dari otonomi dalam pekerjaan yang meningkatkan kemampuan karyawan dan menghasilkan rasa tanggung jawab untuk organisasi (Laschinger $e t$ al., 2000). Namun dalam praktik managemen untuk katerlibatan karyawan dalam mendapatkan pengakuan, karyawan harus berkomitmen untuk insiatif perbaikan kinerja organisasi. Dengan tidak adanya komitmen tersebut, praktik managemen hanya akan menghasilkan kurangnya partisipasi karyawan yang mengarah pada ketidakhadian (Hackman and Wageman, 1995).

Disini, pengetahuan khusus dokter memungkinkan mereka untuk memainkan peran sentral dalam proses pengambilan keputusan di fasilitas pelayanan kesehatan (Anand, Chhajed and Delfin, 2012). Selain itu, layanan kesehatan yang beragam dan heterogen, dan kualitas mereka yang sulit untuk di ukur, manajer tidak dapat sepenuhnya mengamati dan mengevaluasi masukan dan kinerja dokter. Akibatnya dokter diberikan kebijaksanaan untuk melakukan praktik lain atau mengurangi waktu efektif di tempat kerja (Shields and Ward, 2001)

Dari hasil analisis bivariate ditemukan dokter lebih sering tidak hadir. Penelitian ini sejalan dengan temuan Chaudury dan Hammer di Puskesmas Bangladesh, juga Yamada et al dimana dokter menunjukkan tingkat ketidakhadiran yang tinggi dibandingkan dengan petugas Puskesmas yang lainnya. Hal ini mungkin terjadi dokter memiliki otonomi dalam pekerjaanya, kalaupun tidak hadir mereka tidak akan mungkin di pecart karena hal ini. Selain itu sistem pengawasan biasanya lemah, dan kemungkinan sanksi formal rendah. Berbeda dengan hasil penelitian ini, Kivimaki menemukan bahwa dokter memiliki tingkat ketidakhadiran jangka pendek dan jangka panjang yang lebih rendah dibandingkan dengan petugas kesehatan lainnya di Finlandia. Temuan tersebut di dukung oleh penelitian Ritchie et al di Inggris, Isah et al di Nigeria. Hal ini terjadi mungkin dokter menjadi tim pengawas dalam memonitoring petugas puskemas lainnya. Ketidakhadiran petugas kesehatan ini akan meningkatkan kekurangan petugas kesehatan di Puskesmas. Kepala Puskesmas mungkin akan mengalami kesulitan dalam mengubah jadwal kerja dan realokasi tugas pelayanan dari petugas Puskesmas yang tidak masuk kerja ke petugas Puskesmas lainnya yang hadir untuk memastikan keberlanjutan pelayanan. Untuk itu perlu praktik manajemen yang efektif (Nyathi and Jooste, 2008). Sehubungan dengan semakin lama pegawai bekerja disebuah organisasi maka semakin loyal dengan organisasi dan nyaman untuk melakukan tindakan disiplin. Robbins (2003) mengemukakan pegawai yang memilki banyak pengalaman bekerja memilki rasa cinta terhadap pekerjaannya dan memiliki kepuasan kerja yang tinggi dibandingkan dengan yang baru bekerja sehingga pegawai yang memiliki masa kerja yang lama memiliki angka ketidakhadiran yang rendah. Bertentangan dengan yang dikemukakan Robbins, dalam penelitian ini didapat petugas Puskesmas dengan masa kerja diatas tiga tahun memiliki tingkat ketidakhadiran yang tinggi. Hasil tersebut sesuai dengan penelitian Martocchio (1989) yang menyatakan karyawan yang telah bekerja dengan periode waktu yang lama memiliki tingkat ketidakhadiran yang tinggi. penelitian lain oleh Hammer dan Kremer (2008) menyebutkan semakin lama tenaga kesehatan berada pada posisi saat ini semakin besar kemungkinkan kurang berpartisipasi pada pekerjaanya. Hal ini menunjukkan bahwa petugas Puskesmas sudah memilki kenyamanan terhadap pekerjaanya karena merasa sudah bagian dari organisasi sehingga lebih berkomitmen untuk hadir. Namun hasil berbeda didapati dari penelitian (Hoque \& Islam, 2003 ; Ichino \& Riphahn, 2005) dimana pekerja dengan masa kerja yang tinggi memiliki tingkat ketidakhadiran kerja yang 
lebih rendah dibandingkan dengan karyawan dengan masa kerja yang kurang.

Ketidakhadiran tenaga kesehatan merupakan salah satu masalah yang sering di temukan di fasilitas kesehatan dan menjadi hambatan manajemen Puskesmas. Dalam penelitian Chaudhury et al (2006) menyelediki masalah ketidakhadiran tenaga kesehatan Indonesia, data menunjukkan bahwa tingkat ketidakhadiran tenaga kesehatan sebanyak $40 \%$. Sedangkan hasil penelitian ini menunjukkan tingkat ketidakhadiran tenaga kesehatan di Kabupaten Wakatobi sebanyak 24,82\%. Tingginya tingkat ketidakhadiran tenaga kesehatan menjadi bukti bahwa hal ini masih menjadi masalah yang sulit di tangani. Menurut Kelly (2006), kurangnya motivasi, kepuasan kerja, kurangnya pengakuan terhadap kinerja, dan minimnya pengawasan terhadap kehadiran petugas Puskesmas serta lemahnya sanksi menjadi penentu ketidakhadiran petugas Puskesmas. Untuk mengimbangi rekan yang tidak hadir, petugas kesehatan lainnya di bebani dengan pekerjaan tambahan dan kadang-kadang di paksa untuk tugas-tugas yang tidak sesuai dengan kapasitas mereka. Hal ini menjadi demotivasi bagi petugas kesehatan lainnya yang hadir. (Ukho \& Mwanda, 2010)

Robbins (2003) mengemukakan, budaya dan sistem organisasi memainkan peran yang sangat penting dalam pengelolaan ketidakhadiran. Jika dalam suatu organisasi terdapat budaya permisif terhadap ketidakhadiran maka karyawan akan mempertimbangkan sakit cuti untuk di manfaatkan, atau akan mangkir. Disisi lain jika ketidakhadiran mendapat perhatian dari manajemen atau rekan kerja, karyawan akan berpikir dua kali sebelum menyalahgunakan cuti-sakit atau mangkir. Menurut Wananda et al (2015), pemantauan ketat terhadap kehadiran adalah yang terpenting dalam manajemen kehadiran karena memungkinkan manajer untuk mendeteksi besarnya dan tren ketidakhadrain antara karyawan. Hal ini lebih lanjut menjelaskan implementasi praktek manajemen dari kehadiran dan ketidakhadiran yang digunakan fasilitas kesehatan. Perbaikan dalam pelaksanaan praktek managemen di fasilitas pelayanan kesehatan sangat efektif untuk mengurangi ketidakhadiran.

\section{SIMPULAN}

Berdasarkan hasil penelitian untuk membuktikan tujuan dari penelitian, maka dapat disimpulkan bahwa ketidakhadiran petugas
Puskesmas di wilayah Kabupaten Wakatobi masih sangat tinggi. Praktik manajemen

Puskesmas dilihat dari sikap kerja berpengaruh terhadap ketidakhadiran petugas Puskesmas dimana petugas Puskesmas yang memiliki sikap kerja kurang baik lebih sering tidak hadir, kepuasan kerja berpengaruh terhadap ketidakhadiran petugas Puskesmas dimana petugas Puskesmas yang tidak puas memiliki tingkat ketidakhadiran yang lebih tinggi. Supervisi berpengaruh terhadap ketidakhadiran petugas Puskesmas dimana petugas Puskesmas yang mendapatkan supervisi yang kurang baik memiliki tingkat ketidakhadiran yang lebih tinggi

\section{Ucapan Terima Kasih:}

Penelitian ini di biayai oleh Direktorat Riset dan Pengabdian Masyarakat, Direktorat Jenderal Penguatan Riset dan Pengembangan Kementerian Riset, Teknologi, dan Pendidikan Tinggi Sesuai dengan Kontrak Nomor : 109/SP2H/LT/DRPM/2018

\section{DAFTAR PUSTAKA}

Anand, G., Chhajed, D. and Delfin, L. (2012) 'Job autonomy, trust in leadership, and continuous improvement: An empirical study in health care', Operations Management Research, 5(3-4), pp. 7080. doi: 10.1007/s12063-012-0068-8.

Chaudhury, N. and Hammer, J. S. (2003) 'Ghost Doctors: Absenteeism in Bangladeshi Health facilities', (May).

Deussom, R. et al. (2012) 'Holding Health Workers Accountable: Governance Approaches to Reducing Absenteeism. Technical Brief 3', (May).

García-Prado, A. and González, P. (2011) 'Whom Do Physicians Work For? An Analysis of Dual Practice in the Health Sector', Journal of Health Politics, Policy and Law, 36(2), pp. 265-294. doi: 10.1215/03616878-1222721.

Hammer, J. and Kremer, M. (2008) 'Health Personnel Absenteeism in India : Descriptive Statistics and Correlations Preliminary Draft - Please do not quote or reproduce without authors , permission'.

Hoque, M. E. and Islam, M. M. (2003) 'Contribution of Some Behavioural Factors to Absenteeism of 
Manufacturing Workers in Bangladesh', Pakistan Journal of Psychological Research, 18(3-4), pp. 81-95.

Ichino, A. and Riphahn, R. T. (2005) 'The effect of employment protection on worker effort: Absenteeism during and after probation', Journal of the European Economic Association, 3(1), pp. 120143. doi: 10.1162/1542476053295296.

Isah, E. C. et al. (2008) 'Self-reported absenteeism among hospital workers in benin city, Nigeria.', Ghana medical journal, 42(1), pp. 2-7.

Kisakye, A. N. et al. (2016) 'Regulatory mechanisms for absenteeism in the health sector: A systematic review of strategies and their implementation', Journal of Healthcare Leadership, 8, pp. 81-94. doi: 10.2147/JHL.S107746.

Kivimaki, M. (2001) 'Sickness absence in hospital physicians: 2 year follow up study on determinants', Occupational and Environmental Medicine, 58(6), pp. 361-366. doi: 10.1136/oem.58.6.361.

Laschinger et al. (2000) 'Organizational Trust and Empowerment in Restructured Healthcare Settings: Effects on Staff Nurse Commitment', Journal of Nursing Administration, 30(9), pp. 413-425.

Lewis, M. (2009) 'Governance in Health Care Delivery Raising Performance', (October).

Nyathi, M. and Jooste, K. (2008) 'Working conditions that contribute to absenteeism among nurses in a provincial hospital in the Limpopo Province.', 31(1), pp. 28 37.

Pratikno Ramadhan, A. (2013) 'Teacher and health worker absence in Indonesia', Asian Education and Development Studies, 2(2), pp. 149-161. doi: $10.1108 / 20463161311321420$.

Ramadhan, A. P. and Santoso, D. (2015) 'Health workers absenteeism: Indonesia urban public health centres', Journal of Public Health, 23(3), pp. 165-173. doi: 10.1007/s10389-015-0667-6.

Robbins, S. P. (2003) Essentials of Organizational Behaviour. 7th edn. New Jersey: Pearson Education Inc.

Shields, M. A. and Ward, M. (2001) 'Improving nurse retention in the National Health Service in England: the impact of job satisfaction on intentions to quit', Journal of Health Economics, 20(5), pp.
677-701. doi: 10.1016/S01676296(01)00092-3.

The SMERU Research Institute (2004) 'Basic Health Service Delivery at Puskesmas as an Indicator of Good Governance at the Local Level', pp. 1-36.

Yamada, H., Sawada, Y. and Luo, X. (2012) 'Why is Absenteeism Low among

Public Health Workers in Lao PDR?', the journal of development studies, 1(December 2014), pp. 37-41. doi: 10.1080/00220388.2012.700394. 